\title{
A Comparison of Sialic Acid between Different Isolates of Photobacterium damselae subsp. piscicida
}

\author{
Tae S. Jung ${ }^{1 *}$, Kim D. Thompson ${ }^{2}$ and Alexandra Adams ${ }^{2}$ \\ ${ }^{1}$ Laboratory of Fish and Shellfish Diseases, College of Veterinary Medicine, \\ Gyeongsang National University, Chinju, Kyeongnam, 660-701, \\ Republic of Korea \\ ${ }^{2}$ Aquatic Vaccine Unit, Institute of Aquaculture, University of Stirling, \\ Stirling, Scotland, FK9 4LA
}

(Received March 9, 2001)

\begin{abstract}
Sialic acid was identified and compared among 40 strains of Photobacterium damselae subsp. piscicida (formerly, Pasteurella piscicida), isolated from a variety of fish species from geographically different regions. The isolates were divided into two main groups according to the molecular weight of their sialic acid. The first group comprised of 12 Japanese isolates, which contained sialic acid with a molecular weight of $22 \mathrm{kDa}$. The second group included 26 isolates from the Mediterranean region, which contained sialic acid with a molecular weight of $26 \mathrm{kDa}$. A subgroup of Group 2 (2 Mediterranean isolates) was also evident and had a sialic acid molecule of $38 \mathrm{kDa}$. The $P$. damselae subsp. damselae strains (ATCC33539, ATCC35083 and NCIMB2184) had $26 \mathrm{kDa}$ sialic acid molecules. Three isolates representing the three different groups of $P$. damselae subsp. piscicida were treated with Vibrio cholerae Type III sialidase. Isolate OT97299 from Group 1 and isolate SA300695 from the subgroup were both susceptible to the sialidase, while isolate 1736 from the main part of Group 2 was unaffected by the enzyme. All three isolates were susceptible to mild acid treatment.
\end{abstract}

Key words: Photobacterium damselae subsp. piscicida, sialic acid, sialidase, pasteurellosis

The causative agent of pasteurellosis, Photobacterium damselae subsp. piscicida, (formerly Pasteurella piscicida), has been isolated from a variety of fish species cultured in the Mediterranean (Bakopoulos et al., 1995), Japan (Matsuoka and Kamada, 1995) and the USA (Hawke et al., 1987). The disease has been responsible for large economic losses in the aquaculture industry in regions where the infection is prevalent (Thune et al., 1993). As a direct result of this, a great deal of research has focused on the disease. The taxonomy (Gauthier et al., 1995; Thyssen et al., 1998), serology (Magarinos et al., 1992; Salati et al., 1994; Bakopoulos et al., 1997), the route of infection (Magarinos et al., 1996; Kawahara et al., 1989) and the virulence of the pathogen (Magarinos et al., 1994; Noya et al., 1995) have all been examined in detail.

$P$. damselae subsp. piscicida strains produce an additional exostructure (a capsule) when cultured in glucose-enriched medium (Bonet et al., 1994). However, it appears that only virulent strains continually produce a capsular layer in this medium, and it has been shown that bacteria with the capsular layer are resistant to the killing activity of serum sampled from sea bream (Magarinos et al., 1996).

Carbohydrates associated with a number of mammalian bacterial pathogens are known to play an important role in the pathogenesis of the organism, especially sialic acid (Wetzler et al., 1992). Sialic acid present on the surface of bacteria has been shown to inhibit the complement cascade of the host (Varki, 1993), and to protect the bacteria from host antibodies (Jarvis and Vedros, 1987). However, the importance of carbohydrates in the pathogenesis of bacterial fish pathogens remains to be clarified. The aim of the present study was to identify and compare sialic acids among strains of $P$. damselae subsp. piscicida isolated from a variety of fish species from different geographical regions.

\footnotetext{
* Corresponding author

E-mail: jungts@nongae.gsnu.ac.kr
} 


\section{Materials and Methods}

P. damselae subsp. piscicida isolates and culture conditions

Geographical locations and species of fish from which $P$. damselae subsp. piscicida strains were isolated are shown in Table 1. All strains were stored at $-70^{\circ} \mathrm{C}$ on PROTECT® beads (Technical Service Consultants Ltd) until required. They were cultured in tryptone soya broth (TSB) containing $2 \%(w / v) ~ N a C l$ for $16 \mathrm{~h}$ at $22^{\circ} \mathrm{C}$. Three representative strains (I736, OT97299 and SA300695) were continually subcultured on artificial medium during the course of the study. The cultured bacteria were harvested and washed twice with sterile phosphate buffered saline (PBS-1: $0.02 \mathrm{M} \mathrm{NaH}_{2} \mathrm{PO}_{4} \cdot 2 \mathrm{H}_{2} \mathrm{O}$, $\left.0.02 \mathrm{M} \mathrm{Na}_{2} \mathrm{HPO}_{4} \cdot 2 \mathrm{H}_{2} \mathrm{O}, 0.15 \mathrm{M} \mathrm{NaCl}, \mathrm{pH} 7.2\right)$ by centrifugation at $3000 \times g$ for $20 \mathrm{~min}$. Bacterial suspensions were prepared in PBS-1 and their concentrations adjusted to absorbances of 1.0 at $610 \mathrm{~nm}$. This was equivalent to approximately $2 \times 10^{8} \mathrm{CFU} / \mathrm{mL}$, determined

Table. 1. Photobacterium damselae subsp. piscicida and $P$. damselae subsp. damselae strains used in the study and their molecular weights of sialic acid

\begin{tabular}{|c|c|c|c|c|}
\hline Strains & Date isolated & Fish species & Country & ${ }^{*} \mathrm{kDa}$ \\
\hline \multicolumn{5}{|l|}{ subsp. piscicida } \\
\hline $\mathrm{K} 6$ & 1994 & Mullet & Greece & 26 \\
\hline K6a & 1994 & Mullet & Greece & 26 \\
\hline K7 & 1994 & Red Sea Bream & Greece & 26 \\
\hline K8 & 1994 & Sea Bass & Greece & 26 \\
\hline PN1 & 1994 & Sea Bass & Greece & 26 \\
\hline PN2 & 1994 & Sea Bass & Greece & 26 \\
\hline PN3 & 1994 & Sea Bass & Greece & 26 \\
\hline PN510 & 1994 & Sea Bream & Greece & 26 \\
\hline PN510a & 1994 & Sea Bream & Greece & 26 \\
\hline 1736 & 1991 & Sea Bass & Italy & 26 \\
\hline 1746 & 1991 & Sea Bass & Italy & 26 \\
\hline $362-2 / 97$ & 1997 & Sea Bass & Italy & 26 \\
\hline $386 / 97$ & 1997 & Sea Bass & Italy & 26 \\
\hline M28561 & 1985 & Yellow tail & Japan & 22 \\
\hline TPP88003 & 1988 & Yellow tail & Japan & 22 \\
\hline SKP88020 & 1988 & Yellow tail & Japan & 22 \\
\hline TT90009 & 1990 & Yellow tail & Japan & 22 \\
\hline HT90011 & 1990 & Yellow tail & Japan & 22 \\
\hline KP9083 & 1990 & Yellow tail & Japan & 22 \\
\hline SP92065 & 1993 & Yellow tail & Japan & 22 \\
\hline SP92088 & 1993 & Yellow tail & Japan & 22 \\
\hline SP92144 & 1993 & Yellow tail & Japan & 22 \\
\hline SP9351 & 1993 & Yellow tail & Japan & 22 \\
\hline OT-97290 & 1997 & Yellow tail & Japan & 22 \\
\hline ОT-97299 & 1997 & Yellow tail & Japan & 22 \\
\hline SA300695 & 1995 & Sea Bream & Israel & 38 \\
\hline MS020295 & 1995 & Striped bass & Israel & 26 \\
\hline MS011194 & 1995 & Striped bass & Israel & 26 \\
\hline DL270695 & 1995 & Sea bass & Israel & 26 \\
\hline SA040296 & 1996 & Sea bream & Israel & 26 \\
\hline SA071194 & 1994 & Sea bream & Israel & 26 \\
\hline SA120995 & 1995 & Sea bream & Israel & 26 \\
\hline XX000696 & 1996 & Hybrid striped bass & Israel & 26 \\
\hline Spp97127-2 & 1997 & Sea bream & Spain & 26 \\
\hline Spp97127-15 & 1997 & Sea bream & Spain & 26 \\
\hline Spp97127-16 & 1997 & Sea bream & Spain & 26 \\
\hline Spp97127-20 & 1997 & Sea bream & Spain & 38 \\
\hline 231093 & 1993 & Sea bream & Portugal & 26 \\
\hline FR10831 & 1990 & Sea bass & France & 26 \\
\hline $\begin{array}{l}\text { ATCC17911 } \\
\text { subsp. damselae }\end{array}$ & & White perch & & 26 \\
\hline АТССЗ3539 & & Damsel fish & & 26 \\
\hline NCIMB2184 & & Damsel fish & & 26 \\
\hline АТСC 3508 & & Brown shark & & 26 \\
\hline
\end{tabular}

ATCC: American Type Culture Collection

NCIMB: National Collections of Industrial and Marine Bacteria

* Molecular weights of sialic acid of each strain were determined using a commercial glycoprotein detection kit. 
from a standard curve of bacterial concentration versus absorbance at $610 \mathrm{~nm}$. Aliquots of the bacteria were stored at $-70^{\circ} \mathrm{C}$ until required.

\section{Electrophoresis}

Sodium dodecyl sulphate-polyacrylamide gel electrophoresis (SDS-PAGE) was performed on a variety of $P$. damselae subsp. piscicida isolates. Briefly, a $12 \%$ acrylamide separating gel was prepared onto which was layered a $4 \%$ stacking gel. The washed bacteria were prepared in sample buffer as described by Bollag et al. (1996), boiled for $3 \mathrm{~min}$ and centrifuged at $2000 \times g$ for 3 min. The supernatants were placed on the gel $(15 \mu \mathrm{L}$ well) and $180 \mathrm{~V}$ was applied to the gel for $45 \mathrm{~min}$. BioRad or Sigma broad range molecular standard markers were used as standards.

\section{Detection of sialic acid by Western blot analysis}

The bacterial components present in the gel were transferred to a nitrocellulose membrane by applying 60 $\checkmark$ for 70 min using a Hoeffer transblotter (Carlsson, 1993). An Immuno-Blot Kit for glycoprotein determination (Bio-Rad) was used to detect the presence of sialic acid. Reagents were prepared according to the manufacturer's specification. Gentle agitation was applied to the membrane throughout the procedure, except during the development of the reaction. The membrane was washed with cold phosphate buffered saline (PBS-2: $9 \mathrm{mM} \mathrm{NaH}_{2} \mathrm{PO}_{4}, 27 \mathrm{mM} \mathrm{NaCl}, \mathrm{pH}$ 7.2) for $10 \mathrm{~min}$ at $4^{\circ} \mathrm{C}$. It was then immersed in sodium acetate / ethylenediaminetetraacetic acid (EDTA) buffer containing sodium periodate $(100 \mathrm{mM}$ sodium acetate, $5 \mathrm{mM}$ EDTA, $1 \mathrm{mM}$ sodium periodate, $\mathrm{pH}$ 5.5) and incubated in the dark for $20 \mathrm{~min}$ at $4^{\circ} \mathrm{C}$. The membrane was washed three times with PBS-2, washing for 10 min on each wash. A biotinylation solution was prepared immediately before use, by adding $2 \mu \mathrm{L}$ hydrazide solution to 10 $\mathrm{mL}$ sodium acetate / EDTA buffer (without sodium periodate) and the membrane was immersed in this solution for $60 \mathrm{~min}$ at $20^{\circ} \mathrm{C}$. It was then washed 3 times, $10 \mathrm{~min}$ each at $20^{\circ} \mathrm{C}$, with Tris buffered saline (TBS: $50 \mathrm{mM}$ Trisma base, $27 \mathrm{mM} \mathrm{NaCl}, \mathrm{pH} 7.2$ ) and incubated overnight at $4{ }^{\circ} \mathrm{C}$ with $0.5 \%(\mathrm{w} / \mathrm{v})$ ovalbumin in distilled $\mathrm{H}_{2} \mathrm{O}$. It was washed 3 times with TBS the next day as described above. Streptavidin-alkaline phosphatase conjugate was prepared and the membrane was incubated in this solution for $60 \mathrm{~min}$ at $20^{\circ} \mathrm{C}$ before again washing with TBS. The developer was prepared immediately before use by mixing together nitroblue tetrazolium and 5-bromo-4-chloro-3-indolyl phosphate, according to manufacturer's specifications. The membrane was incubated in the solution for 3 to $30 \mathrm{~min}$ at $20^{\circ} \mathrm{C}$ until the required reaction intensity was achieved. The reaction was stopped by rinsing the membrane several times in distilled $\mathrm{H}_{2} \mathrm{O}$.
Treatment of bacteria with sialidase

(a) Treatment of bacteria with sialidase: Treatment of three different $P$. damselae subsp. piscicida strains (OT97299, 1736 and SA300695) with sialidase was performed using a modification of the method described by Ourth and Bachinski (1987). Vibrio cholerae Type III sialidase, which is able to cleave most carbohydrate linkages present in the O-glycan molecule, was used to differentiate between the sialic acids. Briefly, bacteria were washed twice with PBS-1 by centrifugation at 3000 $\times g$ for $20 \mathrm{~min}$, then adjusted to an absorbance of 1.0 at $\mathrm{OD}_{610}$ in sodium acetate buffer ( $100 \mathrm{mM}$ sodium acetate, $1 \mathrm{mM}$ calcium acetate, $100 \mathrm{mM} \mathrm{NaCl} \mathrm{pH} \mathrm{5.5).} \mathrm{The} \mathrm{bac-}$ terial suspension $(1 \mathrm{~mL})$ was placed in autoclaved microcentrifuge tubes at a final concentration of either 20 or 100 mUnits of sialidase was added to the tubes. PBS-1 was also added to a tube as a negative control and 100 $\mathrm{mM}$ in sodium acetate buffer without any bacteria was added to another tube. The tubes were incubated overnight in a shaking water bath, set at $37^{\circ} \mathrm{C}$, after which the bacteria were centrifuged at $12,000 \times g$ for $3 \mathrm{~min}$. Bacterial pellets were resuspended to their previous volume with PBS-1, and these were then mixed with sample buffer for electrophoresis and Western blot analysis using the glycoprotein determination kit.

(b) Treatment of nitrocellulose membrane with sialidase: Alternatively, sialic acid present on the nitrocellulose membrane was exposed to sialidase. The three $P$. damselae subsp. piscicida isolates (OT97299, 1736 and SA300695) were subjected to SDS-PAGE as described above, and transferred to a nitrocellulose membrane. The membrane was washed with $100 \mathrm{mM}$ sodium acetate buffer (three washes, $10 \mathrm{~min}$ each). It was then cut it into two halves, one of which was used as a control and the other was treated at $37^{\circ} \mathrm{C}$ for $4 \mathrm{~h}$ with sialidase at 50 mUnits in $100 \mathrm{mM}$ sodium acetate buffer, $\mathrm{pH}$ 5.5. The membranes were then processed as described above using the glycoprotein determination kit.

\section{Treatment of bacteria with mild acid conditions}

Mild acid hydrolysis was used to release sialic acid from the glyco-conjugates present on the bacterium's surface. The same three strains of $P$. damselae subsp. piscicida as above, were again prepared as previously described. The bacterial suspension was centrifuged at $12,000 \times g$ for $3 \mathrm{~min}$ and the pellet was resuspended in $0.1 \mathrm{M} \mathrm{H}_{2} \mathrm{SO}_{4}$. The bacteria were incubated in the acid conditions for $1 \mathrm{~h}$ at $80^{\circ} \mathrm{C}$ (Manzi and Varki, 1993). Treated bacteria were centrifuged at $12,000 \times \mathrm{g}$ for $3 \mathrm{~min}$ and the pellets were resuspended to pre-treatment volumes with PBS-1. The bacterial samples were applied to SDS-PAGE and performed Western blot analysis to detect sialic acid. 


\section{Results}

Detection of sialic acid on nitrocellulose membranes

Three strains of $P$. damselae subsp. damselae and forty strains of $P$. damselae subsp. piscicida were examined for the presence of sialic acid using a commercially prepared immunoblotting kit. An example of this is shown in Fig. 1. Differences were noted in the sialic acid among the isolates examined (Table 1). It was possible to differentiate between the strains of $P$. damselae subsp. piscicida obtained from Japan and those from the Mediterranean region. All of the isolates from Japan contained a band at approximately $22 \mathrm{kDa}$, regardless of the year in which they were isolated (Group 1). Most of the isolates obtained from the Mediterranean region exhibited a band at approximately 26 kDa (Group 2), except for two isolates (one from Spain, Spp 97127-20 and one from Israel, SA300695) which had a sialic acid band with a molecular weight around 38 $\mathrm{kDa}$. The molecular weight of the sialic acid on isolate

$\mathrm{kDa}$

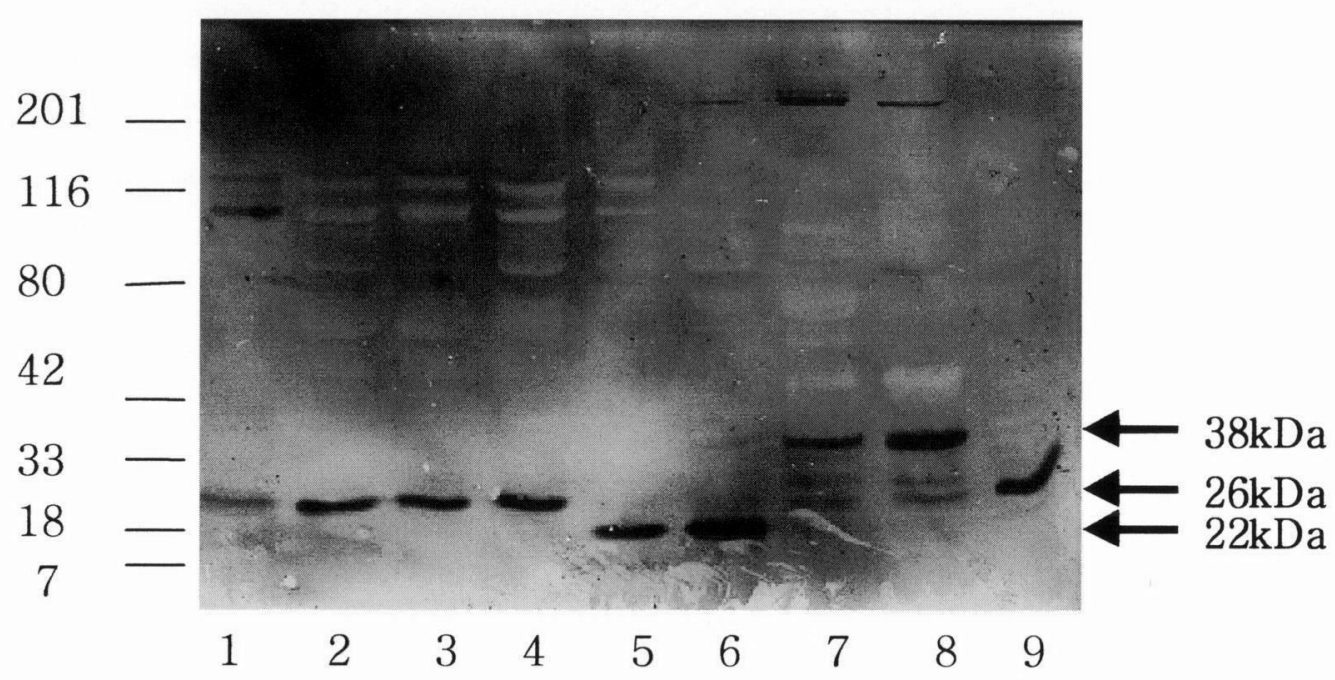

$\mathrm{kDa}$

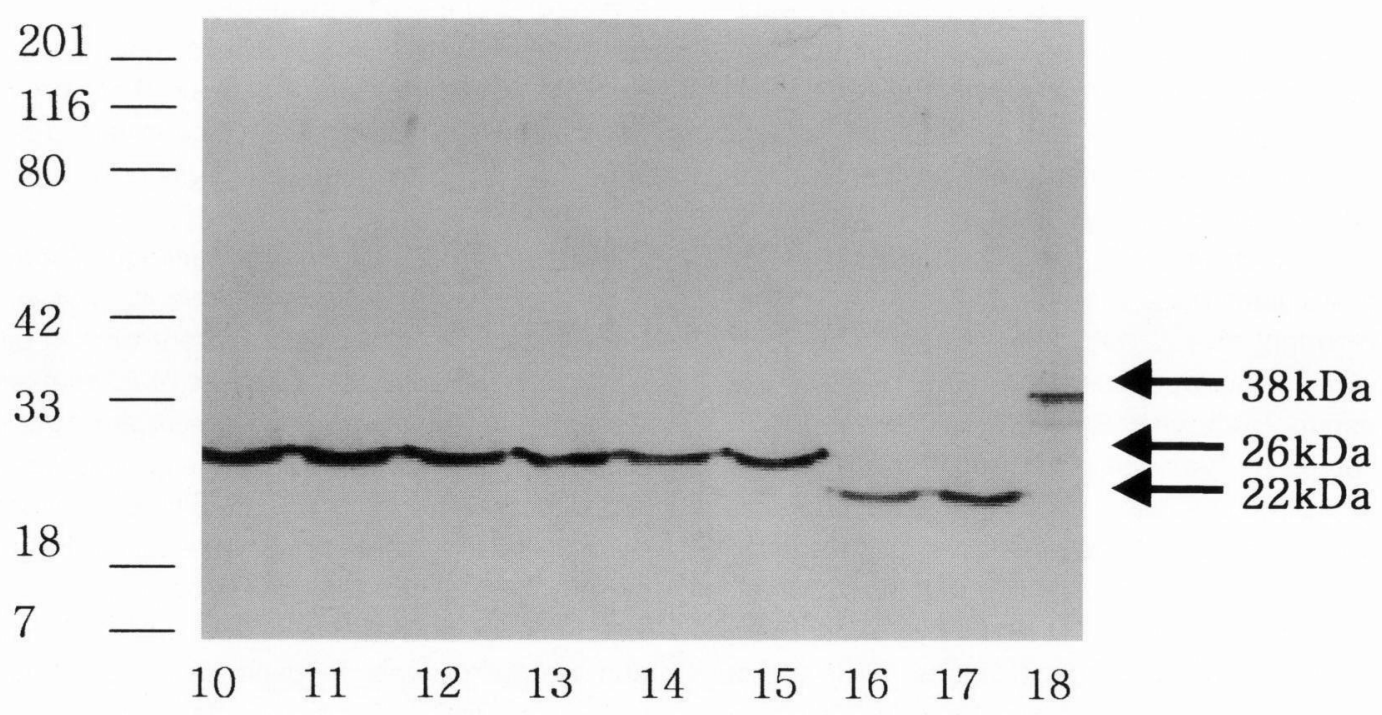

Fig. 1. Sialic acid profiles on strains of Photobacterium damselae subsp. piscicida isolated from fish. Lanes: (1) I736 (Italy); (2) I746 (Italy); (3) K6a (Greece); (4) Pn510a (Greece); (5) SP92144 (Japan); (6) SP9351 (Japan); (7) SA300695 (Israel); (8) Spp97127-20 (Spain); (9) NCIMB 2184 (P. damselae subsp. damselae); (10) I736 (Italy); (11) I746 (Italy); (12) K6a (Greece); (13) Pn510a (Greece); (14) NCIMB 2184 (P. damselae subsp damselae); (15) SA300695 (Israel); (16) SP92144 (Japan); (17) SP9351 (Japan); (18) Spp-97127-20 (Spain). (7 and 15: after several possages on the medium) 
SA300695 was found to change through time from $38 \mathrm{kDa}$ to $26 \mathrm{kDa}$ after several passages on artificial culture medium (Fig. 1). Three strains of P. damselae subsp. damselae was showed the same molecular weight of sialic acid with Group 2 (Fig. 1).

\section{Sialidase treatment}

Vibrio cholerae Type III sialidase was able to cleave sialic acid present on isolates OT97290 from Japan (Group 1) and SA300695 from Israel (subgroup of Group 2), but was unable to cleave sialic acid on isolate 1736 from Italy (main Group 2) (Fig. 2). This was the case

$\mathrm{kDa}$

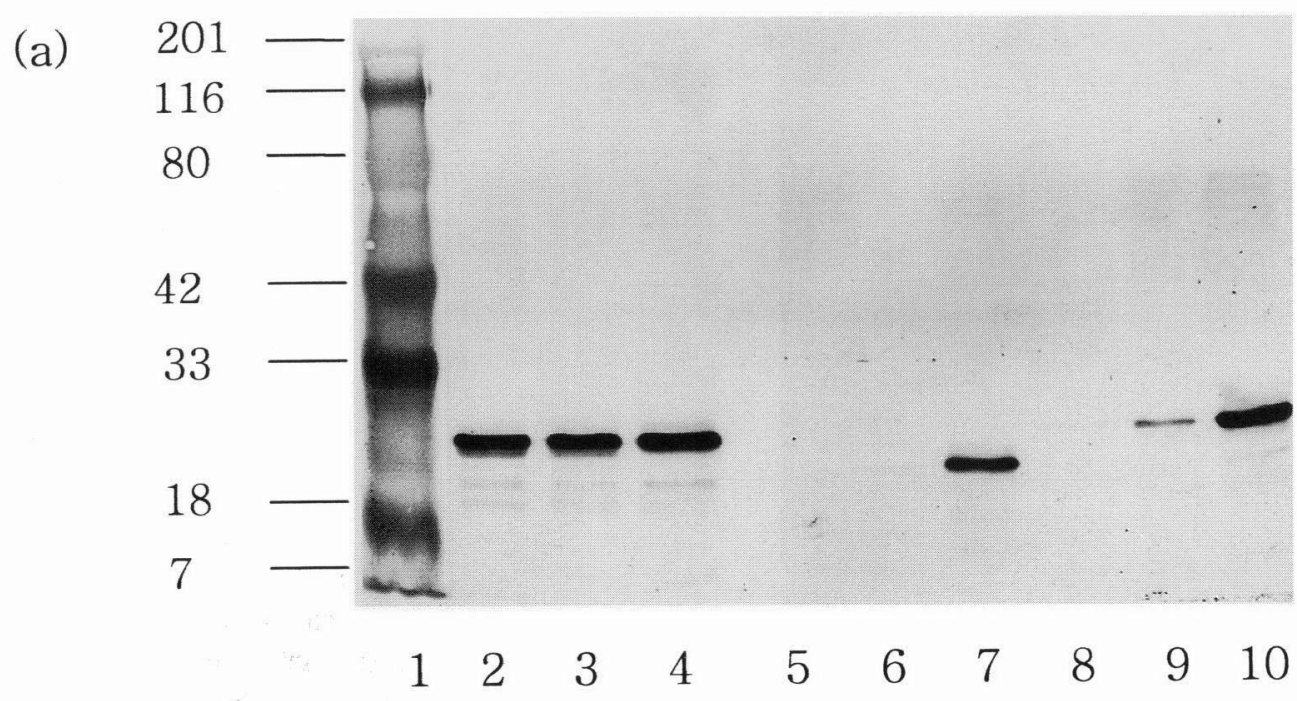

$\mathrm{kDa}$

(b)

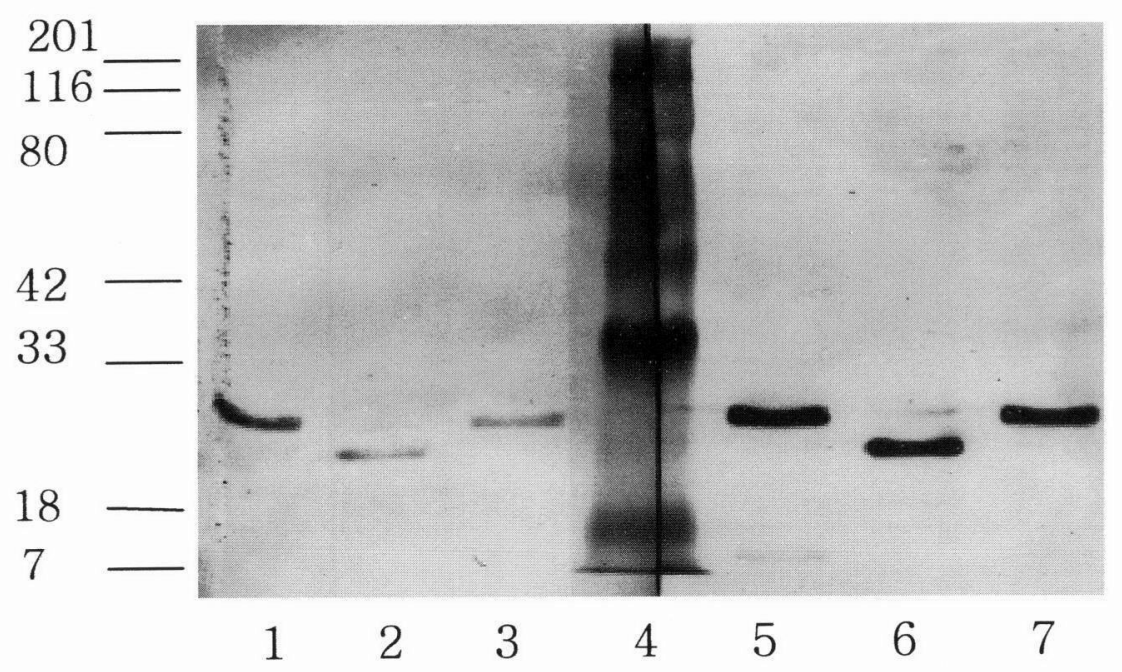

Fig. 2. (a) Detection of sialic acid on three isolates of $P$. damselae subsp. piscicida after direct treatment with sialidase; Lanes: (1) MW markers, (2) treatment of isolate 1736 with 100 mUnit sialidase, (3) treatment of isolate 1736 with 20 mUnit sialidase, (4) isolate 1736 untreated, (5) treatment of isolate OT97299 with 100 mUnit sialidase, (6) treatment of isolate OT97299 with 20 mUnit sialidase, (7) isolate OT97299 untreated, (8) treatment of isolate SA300695 with 100 mUnit sialidase, (9) treatment of isolate SA300695 with 20 mUnit sialidase, (10) isolate SA300695 untreated.

(b) Detection of sialic acid on three isolates of $P$. damselae subsp. piscicida after indirect treatment of the nitrocellulose membrane with sialidase: Lanes: [treated (1) 1736, (2) OT97299, (3) SA300695], (4) MW marker, [untreated (5) SA300695, (6) OT97299, (7) 1736]. 


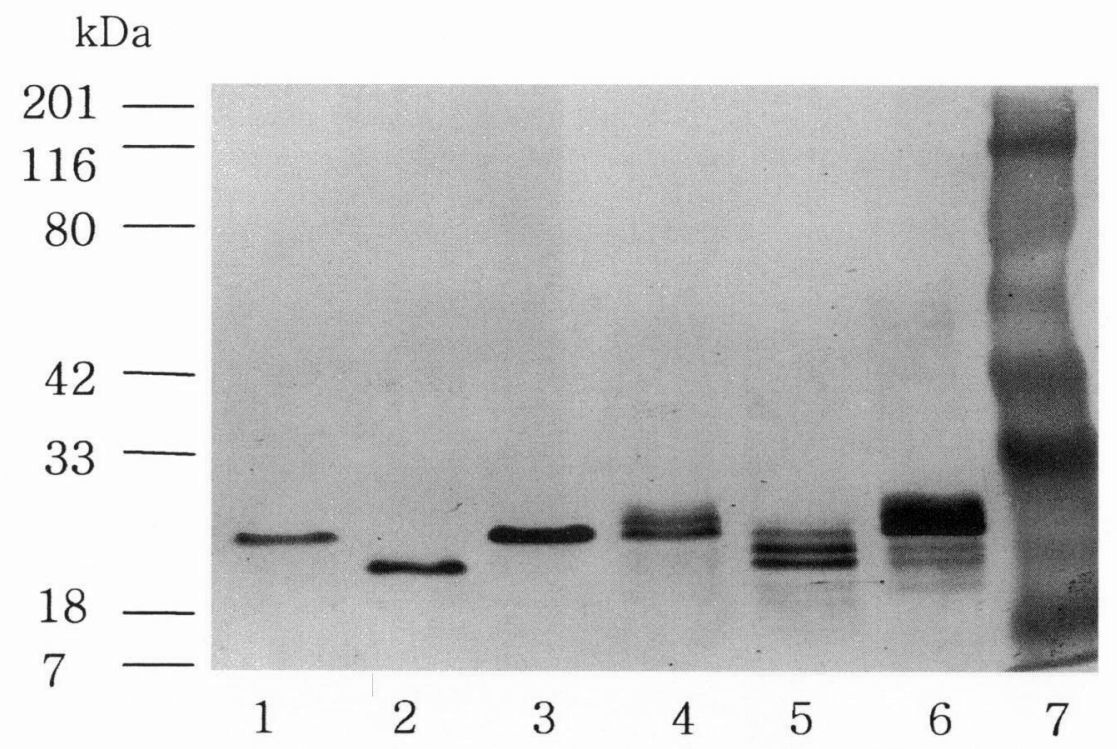

Fig. 3. Detection of sialic acid on three isolates of $P$. damselae subsp. piscicida after mild acid treatment $\left(0.1 \mathrm{M} \mathrm{H}_{2} \mathrm{SO}_{4}\right)$ : Lanes (1) untreated SA300695, (2) untreated OT97299, (3) untreated 1736, (4) acid treated SA300695, (5) acid treated OT97299, (6) acid treated 1736, (7) MW markers.

for both the direct (Fig. 2a) and indirect approaches (Fig. $2 b)$. Incubation of the bacteria directly with sialidase at a concentration of $100 \mathrm{mUnits}$ resulted in complete cleavage of the sialic acid on both isolates OT97290 and SA300695, while a concentration of 20 mUnits resulted in partial cleavage of the sialic acid present on isolate SA300695 (Fig 2a). When the sialic acid from the bacterium was treated indirectly with the sialidase (50 mUnits), by treating the nitrocellulose membrane containing the bacterial components, fainter bands were obtained with isolates OT 97290 and SA 300695 compared with isolate I 736 (Fig. 2b). It should be noted that the sialidase treatment of isolate SA300695 was performed when the molecular weight of its sialic acid was located at $26 \mathrm{kDa}$ and not $38 \mathrm{kDa}$.

\section{Mild acid treatment}

Mild acid treatment of the bacteria with $0.1 \mathrm{M} \mathrm{H}_{2} \mathrm{SO}_{4}$ resulted in cleavage of the sialic acid bands on all three P. damselae subsp. piscicida strains examined (Fig. 3). The sialic acid present on isolate 1736 and OT97299 was cleaved into two strongly stained bands as well as several fainter stained bands. Few bands were cleaved from the sialic acid of isolate SA300695 when treated with acid, however the two major bands were still evident.

\section{Discussion}

Sialic acid is known to have a variety of roles in the pathogenesis of bacteria. Sialic acids and sialyl-oligosaccharides present on many microbial surfaces protect microorganisms from host antibodies and the alternative complement pathway (ACP) (Javis and Vedros,
1987; Wetzler et al., 1992; Varki, 1993). Sialic acid has been located on Escherichia coli K1, group B Streptococcus and Nisseria meningitidis. A polymer of sialic acid in capsular polysaccharide of $E$. coli $\mathrm{K} 1$ has been identified as an important virulence determinant (Annunziato et al., 1995). The terminal sialic acid moiety of the group B Streptococcus type capsule has also been shown as a critical virulence factor (Platt et al., 1994).

Exogenous sialylation of $N$. meningitidis lipo-oligosaccharide causes resistance to serum bactericidal activity (Jarvis and Vedros, 1987). The relationship between sialic acid on fish pathogens and its ability to inhibit the complement of fish remains to be elucidated. Little research has been performed in this area, however, Ourth and Bachinski (1987) examined 15 different Gram-negative bacteria, pathogenic or non-pathogenic to fish, for the presence of sialic acid. They found very little bactericidal activity of the ACP of catfish against the fish pathogens that contained sialic acid, but a very strong bactericidal response against the non-pathogens, which lacked sialic acid. Treatment of the bacterial fish pathogens with sialidase to remove sialic acid greatly increased the response of catfish ACP against the bacteria compared to untreated bacteria. Sialic acid is believed to play an important role in pathogenicity of bacterial pathogens, and that is why sialic acid analysis of $P$. damselae subsp. piscicida was performed in the present study.

The glycoprotein determination kit was very effective in differentiating the sialic acids present on the $P$. damselae subsp. piscicida isolates, and in providing their molecular weight. The sialic acid determination kit identified a sialic band at approximately $22 \mathrm{kDa}$ on all 
twelve isolates obtained from yellowtail (Seriola quinqueradiata) infected with pasteurellosis in Japan between 1985 and 1997. Most of the isolates obtained from fish infected in the Mediterranean region, that is 26 isolates collected from a variety of fish species cultured in Greece, Italy, Israel, Spain, Portugal or France, had a band representing sialic acid at approximately 26 $\mathrm{kDa}$. Two isolates, from Spain (Spp97127-20) and Israel (SA300695), displayed a band around $38 \mathrm{kDa}$. The molecular weight of the latter isolate (SA300695) was found to have changed to $26 \mathrm{kDa}$ after repeated subculturing on an artificial medium. Sialic acid analysis showed not only a difference between the various geographical isolates but also etiological differences in terms of their sialic acid structure. Three $P$. damselae subsp. damselae were compared with $P$. damselae subsp. piscicida isolated from fish with respect to the homogeneity of their sialic acid content. No differences were found between $P$. damselae subsp. damselae and the Mediterranean isolates of $P$. damselae subsp. piscicida analysed in this study.

Three representative isolates of $P$. damselae subsp. piscicida, chosen because they contain sialic acid with different molecular weights, were treated with Vibrio cholerae Type III sialidase. The sialidase used is able to cleave most linkages in the O-glycan structure, but has a relatively high susceptibility for the following linkages: Neu5Ac $\alpha 2 \rightarrow 3$, Neu5Gc $\alpha 2 \rightarrow 3,7$ (9) mono-Oacetyl Ac $\alpha 2 \rightarrow 3$ (Manzi and Varki, 1993). The enzyme was able to cleave sialic acid present on isolates OT97290 from Japan and SA300695 from Israel. The susceptibility of the bacteria for sialidase activity confirms that $P$. damselae subsp. piscicida clearly contains sialic acid either as part of a polysaccharide molecule or a glycoprotein molecule. Where exactly it is located remains to be elucidated, but the results of this study suggest that it is situated on the surface of the bacterium, since treating whole bacteria with the enzyme resulted in sialic acid digest. However, it was unable to cleave the sialic acid present on isolate 1736 from Italy when incubated directly with the bacteria or indirectly on the nitrocellulose membrane. When it was incubated directly with the bacteria, at a concentration of 100 mUnit, it was able to cleave the sialic acid from both isolates OT97290 and SA300695. A concentration of 20 mUnit was found insufficient to completely cleave the sialated moiety on isolate SA300695. The sialic acid present on isolate OT9720 may have a slightly different structure to isolate SA 300695. By treating the sialic acid on the nitrocellulose membrane, fainter bands resulted with both isolate OT97290 and SA300695 compared to isolate 1736.

Mild acid hydrolysis is known to release sialic acid from glyco-conjugates, but can result in extensive destruction of the O-acetyl group. It is, however, useful for releasing silaic acid from the surface of the bacterium (Manzi and Varki, 1993). Mild acid treatment proved the cleavage of the sialic acid bands of all three $P$. damselae subsp. piscicida strains examined.

\section{REFERENCES}

Annunziato, P. W., L. F. Wright, W. F. Vann and R. P. Silver (1995): Nucleotide sequence and genetic analysis of the neuD and neuB genes in region 2 of the polysialic acid gene cluster of Escherichia coli K1. J. Bacteriol., 177, 312-331.

Bakopoulos, V., A. Adams and R. H. Richards (1995): Some biochemical properties and antibiotic sensitivities of Pasteurella piscicida isolated in Greece and comparison with strains from Japan, France and Italy. J. Fish Dis., 18, 1-7.

Bakopoulos, V., A. Adams and R. H. Richards (1997): Serological relationship of Photobacterium damselae subsp. piscicida isolates (the causative agent of fish pasteurellosis) determined by Western blot analysis using six monoclonal antibodies. Dis. Aquat. Org., 28, 69-72.

Bollag, M. D., D. M. Rozycki, J. Stuart and J. S. Edelstein (1996): Gel electrophoresis under denaturing conditions. In "Protein Method". Wiley-Liss, New York, pp. 95-139.

Bonet, R., B. Magarinos, J. L. Romalde, M. D. Simon-Pujol, A. E. Toranzo and F. Congregado (1994): Capsular polysaccharide expressed by Pasteurella piscicida grown in vitro. FEMS Microbiol. Lett., 124, 285-289.

Carlsson, R. S. (1993): Isolation and characterization of glycoproteins. In "Glycobiology: a practical approach" (Ed by M. Fukuda and A. Kobata). Oxford University Press. pp. 125.

Gauthier, G., B. Lafay, R. Ruimy, V. Breittmayer, J. L. Nicolas, M. Gauthier and R. Christen (1995): Small-subunit rRNA sequences and whole DNA relatedness concur for the reassignment of Pasteurella piscicida to the Genus Photobacterium as Photobacterium damsela subsp. piscicida comb. nov. Int. J. Syst. Bacteriol., 45,139-144.

Hawke, J. P., S. M. Plakas, R. V. Minton, R. M. McPhearson, T. G. Snider and A. M. Guarino (1987). Fish pasteurellosis of cultured striped bass (Morone saxatilis) in coastal Alabama. Aquaculure, 75, 193-204.

Jarvis, G. and N. A. Vedros (1987): Sialic acid of group B Neisseria meningitidis regulates alternative complement pathway activation. Infect. Immun., 55, 174-180.

Kawahara, E., K. Kawai and R. Kusuda (1989): Invasion of Pasteurella piscicida in tissues of experimentally infected yellowtail Seriola quinqueradiata. Bull. Jap. Soc. Sci. Fish., 55, 499-501.

Magarinos, B., J. L. Romalde, I. Bandin, B. Fouz and A. E. Torazo (1992): Phenotyping, antigenic, and molecular characterization of Pasteurella piscicida strains isolated from fish. Appl. Environ. Microbiol., 58, 3316-3322.

Magarinos, B., J. L. Romalde, M. L. Lemos, J. L. Barja and A. E. Toranzo (1994): Iron uptake by Pasteurella piscicida and its role in pathogenicity for fish. Appl. Environ. Microbiol., 60, 2990-2998.

Magarinos, B., R. Bonet, J. L. Romalde, M. J. Martinez, F. Congregado and A. E. Toranzo (1996): Influence of the capsular layer on the virulence of Pasteurella piscicida for fish. Microb. Pathol., 21, 289-297.

Manzi, E. A. and A. Varki (1993): Compositional analysis of glycoproteins. In "Glycobiology: a practical approach" (ed by M. Fukuda and A. Kobata). Oxford University Press, pp 27-76.

Matsuoka, S. and S. Kamada (1995): Discharge of Pasteurella piscicida cells from experimentally infected yellowtail. Fish Pathol., 30, 221-225. 
Noya, M., B. Magarinos and J. Lamas (1995): Interactions between peritoneal exudate cells (PECs) of gilthead seabream (Sparus aurata) and Pasteurella piscicida. A morphological study. Aquaculture, 131, 11-21.

Ourth, D. D. and L. M. Bachinski (1987): Bacterial sialic acid modulates activation of the alternative complement pathway of channel catfish (Ictalurus punctatus). Dev. Comp. Immunol., 11, 551-564.

Platt, M. W., N. Correa Jr. and C. Mold (1994): Growth of group $B$ streptococci in human serum leads to increased cell surface sialic acid and decreased activation of the alternative complement pathway. Can. J. Microbiol., 40, 99-105.

Salati, F., G. Giorgetti and R. Kusuda (1994): Comparison among strains of Pasteurella piscicida from Japan, Italy and USA. Riv. Ital. Acquacolt., 29, 133-139.
Thune, L. R., A. L. Stanley and K. R. Cooper (1993): Pathogenesis of gram-negative bacterial infections in warmwater fish. In "Annual Review of Fish Diseases" (ed. by M. Faisal and F. M, Hetrick), Pergman Press, 3, 39-68.

Thyssen, A., L. Grisez, R. van Houdt and F. Ollevier (1998): Phenotypic characterization of the marine pathogen Photobacterium damselae subsp. piscicida. Int. J. Syst. Bacteriol., 48, 1145-1151.

Varki, A. (1993): Biological roles of oligosaccharides: all of the theories are correct. Glycobiol., 3, 97-130.

Wetzler, L. M., K. Barry, M. S. Blake and E. C. Gotschlich (1992): Gonococcal lipo-oligosaccharide sialylation prevents complement-dependent killing by immune sera. Infect. Immun., 60, 39-43. 